\title{
Appendix 1: Patient Information Sheets: Pull-Out Sheets of Practical Allergen Avoidance Advice
}

\author{
House Dust Mite Allergen Reduction
}

Aims to reduce the amount of mite allergens in the home

Major Strategies (WHO Strength of Recommendation A)

- Wash bedding regularly (every $1-2$ weeks) at $55-60^{\circ} \mathrm{C}$, if possible, to kill mites (washing with cold water removes $90 \%$ of mite allergens; washing at $55-60^{\circ} \mathrm{C}$ kills mites but does not denature mite allergens)

- Wash pillows and duvets in hot water $55-60^{\circ} \mathrm{C}$, and encase pillows and mattresses with documented protective coverings

- Latin-American Network of Human Genetics Sufficient ventilation of dwellings to decrease humidity; aim to reduce indoor relative humidity to below $50 \%$ and avoid damp housing conditions

\section{Additional Strategies}

- $\quad$ Use a good quality vacuum cleaner (if possible one fitted with HEPA filter)

- Use a damp duster when dusting and cleaning surfaces

- Replace wall-to-wall carpets with linoleum or wooden floors which can be wiped clean

- $\quad$ Remove/reduce curtains and soft furnishings in the bedroom

- $\quad$ Replace fabric-covered seating with leather or vinyl

- Remove soft toys from the bedroom; wash them at $55-60^{\circ} \mathrm{C}$ or freeze them (in a kitchen deep-freezer) to kill house dust mites

- Do not allow pets in the bedroom

- House dust mites are transparent and have no natural protection against sunlight; exposure of mattresses, rugs and carpets to direct strong sunlight (for more than $3 \mathrm{~h}$ ) kills mites and can be used in appropriate regions.

- A hammock, easily washable and susceptible to air and sun drying, is used in many areas of the world 


\section{Pollen Avoidance}

Provides mechanical barriers to pollen contact

- Keep windows closed at peak pollen times, e.g. in the evening when airborne pollens descend to lower altitudes

- Wear glasses or sunglasses to prevent pollens entering the eyes

- Consider wearing a mask over the nose and mouth to prevent inhalation of pollens at peak time

- Do not cut grass yourself

- Keep windows closed when the grass has been mown

- Use air-conditioning if possible

- Install car pollen filters if possible

\section{Pet Allergen Avoidance}

Reduces the amount of pet allergen indoors

- If possible, find another home for the pet, and do not bring new animals into the home

- Exclude pets from bedrooms and if possible keep pets outdoors

- Vacuum carpets, mattresses and upholstery regularly, if a power source and equipment are available

- Change clothes before going to school/work if you have attended your horse/cat/dog 


\section{Cockroach Allergen Avoidance}

Removes the cockroaches, eliminates the places and conditions in which they can live, and removes allergens

- $\quad$ Eradicate cockroaches with appropriate insecticides

- Seal cracks in floors and ceilings

- Remove sources of food

- Control dampness

- Scrub floors with water and detergent to remove allergens

- $\quad$ Bedding, curtains and clothing can be contaminated and must be washed

\section{Mould Allergen Avoidance}

Prevents mould from growing, and mould spores from becoming airborne during mould removal

\section{Indoors}

- Use dehumidifiers in the home if relative humidity is constantly high (above 50\%)

- Ensure heating, ventilation or air-conditioning systems are properly maintained

- Use 5\% ammonia solution to remove mould from bathrooms and other contaminated surfaces

- $\quad$ Replace carpets with hard flooring; replace wallpaper with paint

- $\quad$ Repair indoor water damage immediately

\section{Outdoors}

- $\quad$ Avoid cutting grass in late summer when mould spores are present in decaying vegetation 


\section{Severe Reactions, Allergic Anaphylaxis}

Aims to prevent contact with the allergens that induce anaphylaxis in susceptible individuals, and to provide strategies for dealing with episodes of allergic anaphylaxis

- Carry an epinephrine auto-injector and know how and when to use it; always have a spare auto-injector available

- Carry an emergency pager or mobile telephone to call assistance

- Carry/wear MedicAlert information

- When travelling abroad, carry an anaphylaxis-alert card in the language of the country being visited, detailing food, drug, and insect allergies

- Avoid stinging insects, and learn how not to attract them:

- do not wear perfumes or bright colours

- do not pick ripe fruits, and avoid refuse bins and compost heaps which attract insects

- keep car windows closed when driving

- Avoid allergenic ingredients in ready-made food by learning how to interpret ingredient lists

- If eating out check with the chef that allergenic foods/oils are not used in dishes; explain the significance of avoiding allergenic ingredients

In the school environment

- $\quad$ Ensure that parents, teachers, fellow students, and school administrators are aware of the necessity to provide a safe environment for children at risk for anaphylaxis to foods or insect stings

- $\quad$ Create a no-food area of the school playground

- Identify a supervisor to carry a telephone for emergencies

In the occupational environment

- Avoid contact with airborne or contact allergens; for example, airborne latex can be avoided by co-workers using powder-free latex gloves 